\title{
Work Disability in Early Systemic Sclerosis: A Longitudinal Population-based Cohort Study
}

\section{Gunnel Sandqvist, Roger Hesselstrand, Ingemar F. Petersson, and Lars Erik Kristensen}

ABSTRACT. Objective. To study work disability (WD) with reference to levels of sick leave and disability pension in early systemic sclerosis (SSc).

Methods. Patients with SSc living in the southern part of Sweden with onset of their first non-Raynaud symptom between 2003 and 2009 and with a followup of 36 months were included in a longitudinal study. Thirty-two patients (26 women, 24 with limited SSc) with a median age of 47.5 years (interquartile range 43-53) were identified. WD was calculated in 30-day intervals from 12 months prior to disease onset until 36 months after, presented as the prevalence of WD per year (0-3) and as the period prevalence of mean net days per month $( \pm$ SD). Comparisons were made between patients with different disease severity and sociodemographic characteristics, and between patients and a reference group (RG) from the general population.

Results. Seventy-eight percent had no WD 1 year prior to disease onset, which decreased to $47 \%$ after 3 years. The relative risk for WD in patients with SSc compared with RG was 0.95 (95\% CI 0.39-2.33) at diagnosis, and increased to $2.41(1.28-4.55)$ after 3 years. There were no significant correlations between WD and disease severity, but between WD and years at workplace $\left(\mathrm{r}_{\mathrm{s}}=-0.72 ; \mathrm{p}=0.002\right)$, education $\left(\mathrm{r}_{\mathrm{s}}=-0.51 ; \mathrm{p}=0.004\right)$, and sickness absence the month before disease onset $\left(\mathrm{r}_{\mathrm{s}}=0.58\right.$; $\mathrm{p}=0.001)$, respectively.

Conclusion. Considerable increase in WD was noted 3 years after disease onset. Limited education, fewer years at workplace, and sickness absence before disease onset may be risk factors for sustained WD. (First Release August 1 2015; J Rheumatol 2015;42:1794-1800; doi:10.3899/jrheum.150023)

Key Indexing Terms:

SYSTEMIC SCLEROSIS WORK DISABILITY LONGITUDINAL STUDIES
Work is a major component of daily life for most adults. People work to make a living, but work also creates routines and structure in everyday life. Work disability (WD) is common among persons with rheumatic diseases, and may contribute to loss of life roles and social status, and lead to

From the Department of Clinical Sciences, Section of Rheumatology, and Orthopedics, Department of Clinical Sciences, Lund University; Epidemiology and Register Centre South, Skåne University Hospital, Lund, Sweden; Musculoskeletal Statistics Unit, The Parker Institute, Department of Rheumatology, Copenhagen University Hospital, Bispebjerg and Frederiksberg, Denmark.

Supported by unrestricted grants from the Swedish Medical Research Council, the Medical Faculty of Lund University, the Swedish Rheumatism Association, Norrbacka-Eugenia Fund, King Gustaf V 80-year Fund, the Österlund Foundation, the Oak Foundation, and the Kock Foundation.

G. Sandqvist, RegOT, PhD, Department of Clinical Sciences, Section of Rheumatology, Lund University; R. Hesselstrand, $M D, P h D$, Department of Clinical Sciences, Section of Rheumatology, Lund University; I.F. Petersson, MD, PhD, Orthopedics, Department of Clinical Sciences, Lund University, and Epidemiology and Register Centre South, Skåne University Hospital; L.E. Kristensen, $M D, P h D$, Department of Clinical Sciences, Section of Rheumatology, Lund University, and Musculoskeletal Statistics Unit, The Parker Institute, Department of Rheumatology, Copenhagen University Hospital.

Address correspondence to Dr. G. Sandqvist, Section of Rheumatology, Department of Clinical Sciences, Lund University, SE-221 85 Lund, Sweden.E-mail: gunnel.sandqvist@med.lu.se

Accepted for publication June 5, 2015. adverse economic consequences for the individual and for society ${ }^{1,2}$. Prevalence and risk factors for WD are extensively studied in chronic arthritis, and sick leave (SL) at the onset of disease, type of work, older age, and disease activity have been identified as risk factors for WD in chronic arthritis $3,4,5$. WD and risk factors for SL are, however, significantly less studied in connective tissue diseases such as systemic lupus erythematosus (SLE) and systemic sclerosis (SSc), which is unsatisfactory because these diseases also affect individuals of working age.

SSc is a rare chronic connective tissue disease; prevalence in southern Sweden has been reported as 235 per million inhabitants and incidence as 14 per million inhabitants ${ }^{6}$. The disease is characterized by microvascular injury and excessive fibrosis of the skin and internal organs ${ }^{7}$ that influence the individual in various ways, including performance of activities of daily life $e^{8,9,10}$. Studies to date indicate that the prevalence of WD is high in SSc, even higher than in rheumatoid arthritis (RA) ${ }^{11}$. Cross-sectional studies have shown that $21-55 \%$ of individuals with a disease duration of about 10 years were outside the workforce, and that disease severity, pain, fatigue, physical function, and reduced hand function were factors related to $\mathrm{WD}^{11,12,13}$. But WD is already a problem in early disease. Sharif, et $a l^{14}$

Personal non-commercial use only. The Journal of Rheumatology Copyright @ $\odot$ 2015. All rights reserved 
found that $43 \%$ of individuals with SSc [57\% with diffuse cutaneous SSc $(\mathrm{dcSSc})]$ were work disabled within 5 years after disease onset, and 4 years later, an additional $26 \%$ had become work disabled. Longterm SL is generally a risk factor for disability pension (DP) and may start a process of marginalization from the labor market with negative consequences for the individual and for the society ${ }^{15}$.

However, to identify patients with needs for early interventions, e.g., medical treatment and rehabilitation, more knowledge about patterns of WD and its relationship to disease activity in early disease is needed. The aim of our study was to examine longitudinal WD with reference to levels of SL and DP in early SSc.

\section{MATERIALS AND METHODS}

Study design. Our study had a longitudinal design, enrolling patients with non-Raynaud symptom $\leq 12$ months and with a followup period of 3 years after disease onset. Comparisons were made between patients with different disease severity, as well as sociodemographic characteristics, at baseline. The level of total WD per month (net days of SL or DP) was compared with a reference group (RG). For each patient with SSc, we randomly selected 4 reference controls from the Population and Housing Census database at Statistics Sweden. The controls were matched for age, sex, area of residence, and date of SL start. Each participant's unique personal identification number was linked to the payment register by the Swedish Social Insurance Agency (SSIA), including data on SL and DP. Hypothesis: disease severity, prior status of SL, type of work, and age are related to WD. Patients with SSc have a higher longitudinal WD than the RG.

Ethical considerations. Our study was conducted in accordance to the Declaration of Helsinki principles and was approved by the regional ethics committee. The patients were orally informed about the aim of our study and gave written consent to participate. Cross-linking data from the SSIA with healthcare data was approved by the local ethics committee in Lund (No. 301/2007).

Patients. Those eligible for our study were patients diagnosed and assessed in our department and who met the following conditions: (1) met the American College of Rheumatology criteria for SSc ${ }^{16}$, (2) lived in the Skåne region (the southern part of Sweden), (3) aged between 19 and 61 years, (4) had their first non-Raynaud symptom between January 2002 and December 2009, and (5) had a followup of 36 months (Figure 1).

Demographic and clinical characteristics are presented in Table 1.

Data collection. Sociodemographics at baseline were age at disease onset, sex, type of work, and education. Number of years at workplace was registered in 16 patients in the medical records. Current work was based on the
Table 1. Demographic and clinical characteristics. Values are $\mathrm{n}(\%)$ or median (IQR).

\begin{tabular}{|c|c|}
\hline Characteristics & Values \\
\hline Female & $26(81)$ \\
\hline lcSSc & $24(75)$ \\
\hline Centromeric antibodies & $10(31)$ \\
\hline Antitopoisomerase I antibodies & $4(12)$ \\
\hline RNA polymerase III antibodies & $5(16)$ \\
\hline \multicolumn{2}{|l|}{ Education** } \\
\hline Primary & $11(34)$ \\
\hline Secondary & $10(31)$ \\
\hline College & $9(28)$ \\
\hline \multicolumn{2}{|l|}{ Professions } \\
\hline \multicolumn{2}{|l|}{ Predominantly mental demands with } \\
\hline light physical demands & $8(25)$ \\
\hline Combination of mental and physical & demands \\
\hline Hard physical demands & $12(38)$ \\
\hline Out of workforce & $1(3)$ \\
\hline \multicolumn{2}{|l|}{ No. yrs at current workplace } \\
\hline $0-5$ & 5 \\
\hline$>5$ & 11 \\
\hline \multicolumn{2}{|l|}{ Clinical characteristics, yes, $n=24$} \\
\hline Scars* & $9(28)$ \\
\hline Ulcers $^{\dagger}$ & 0 \\
\hline Gastrointestinal symptoms $s^{\ddagger}$ & $10(31)$ \\
\hline Skin score ${ }^{* *}, 0-51$ points & $\begin{array}{l}8(4-19), \text { lsSSc } 6(3-9) \\
\text { dcSSc } 21.5(12-32)\end{array}$ \\
\hline $\mathrm{VC}, \%$ of the predicted normal value & $\begin{array}{c}92.5(78-103) \\
\text { 1sSSc } 91(75-99) \\
\text { dcSSc } 102(90-109)\end{array}$ \\
\hline HAMIS $^{\dagger}, 0-54$ points & $\begin{array}{c}7 \text { (2.5-15.5), 1sSSc } 7(1-11) \\
\text { dcSSc } 17.5(7-30)\end{array}$ \\
\hline Grippit ${ }^{\dagger}$, Newton & $\begin{array}{c}20(63.5-188), \text { lsSSc } 146(64-208), \\
\text { dcSSc } 110(71-122)\end{array}$ \\
\hline
\end{tabular}

* 1 missing. $* * 2$ missing. ${ }^{\dagger} 3$ missing. $\stackrel{\ddagger}{ } 4$ missing. IQR: interquartile range; SSc: systemic sclerosis; lcSSc: limited cutaneous SSc; VC: vital capacity; HAMIS: hand mobility in scleroderma test; dcSSc: diffuse cutaneous SSc.

findings of de Zwart, et $a l^{17}$, and grouped into 3 categories: (1) predominantly mental demands with light physical demands, (2) a combination of mental and physical demands, and (3) heavy physical demands. Disease duration was defined as time from onset of first non-Raynaud symptom. Skin involvement was subdivided into dcSSc and limited cutaneous SSc (lcSSc). Twenty-four of the patients had already visited the department during the

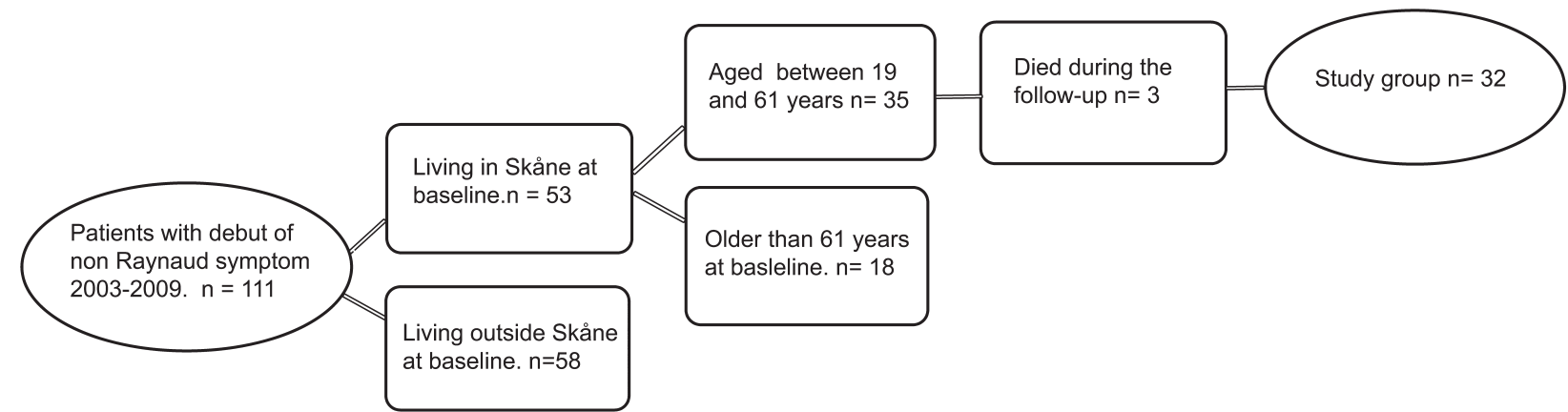

Figure 1. Flowchart for patients with SSc in the Skåne region of Sweden, and the selection process for our study. Our study consists of 32 patients with a median age of 48 years (IQR 43-53). SSc: systemic sclerosis; IQR: interquartile range.

Personal non-commercial use only. The Journal of Rheumatology Copyright @ 2015 . All rights reserved 
first year after disease onset. Disease-related variables such as pulmonary function, skin involvement, gastrointestinal symptoms, and hand function were noted. Pulmonary function was determined by vital capacity, as measured with a Bernstein spirometer. The results are reported as a percentage of the predicted normal value $(\mathrm{p} \%)$. Skin involvement was quantified using the modified Rodnan skin score based on palpation of 17 anatomic sites scored on a $0-3$ scale $^{18}$. Digital vascular lesions were defined as absence or presence of digital tip ulcerations or pitting scars. Hand function was assessed with the hand mobility in scleroderma test (HAMIS) ${ }^{19}$, and grip force with the Grippit instrument ${ }^{20}$. The mean of the average strength in Newtons over $10 \mathrm{~s}$ in both hands is presented. The department's physicians and occupational therapist had performed the investigations and all data were systematically retrieved from the medical record for each patient.

Outcome variables. Primary outcomes for our study were the net days of SL and DP (1 yr before disease onset, and at the followup points) among patients with SSc compared with the RG. The 2 compensation forms were analyzed jointly, denoted WD, but also separately for descriptive purposes. WD calculations were the proportion of WD in 30-day intervals from 12 months before disease onset until 36 months after and the mean level of net days per year. Our study was based on patient data within the context of our prospective followup, and information on SL and DP was retrieved from an independent source, the SSIA through the Epi-centrum Skåne. Data from the Epi-centrum were available from 2002. Compensation < 14 days was not calculated because this was not compensated or registered by the Social Insurance Agency. The compensation forms may be complete (100\%) or partial $(25 \%$, $50 \%$, or $75 \%$ ). Net days were therefore calculated by multiplying the degree of compensation with the number of days. This meant that, for example, 1 net day may equal 1 day with $100 \%$ SL or DP, 2 days with $50 \%$ SL or DP, or 1 day with $25 \%$ DP and $75 \%$ SL. Secondary outcomes were the changes of the degree of WD, and predictors of WD 3 years after disease onset. By summing net days of WD during the first 3 years, we calculated the mean of WD in the early phase of the disease. This was named "the overall WD."

Statistics. Baseline characteristics of patients were presented as median and interquartile range, and as numbers and percentages. WD was calculated in 30-day intervals from 12 months prior to disease onset until 36 months after.
Data are presented both as the period prevalence of WD per year (0-3) and as the period prevalence of mean net days per month $( \pm \mathrm{SD})$. We calculated the relative risk with $95 \% \mathrm{CI}$ to compare WD in patients with SSc with the RG. Spearman rank correlation and the Mann-Whitney U test were used to identify possible associations between WD and disease severity and demographic variables. Wilcoxon signed-rank test was used to test for differences in net days between the baseline and the followup values. Based on prior research, we hypothesized that patients with a high degree of disease severity, old age, and SL before disease onset had a higher degree of WD at the followup and higher degree of an overall WD during the followup.

\section{RESULTS}

WD from disease onset and 3 years after debut onset. Twenty-five patients (78\%) had no WD the year before disease onset, but both the number of patients and the net days per year increased during the first 2 years, and at the 3 -year followup, 8 patients (25\%) were disabled more than 90 days and 7 (22\%) had fulltime WD (Figure 2). Differences in net days of WD between patients and the RG appeared in the later part of the first year, and persisted during the followup period (Figure 3A). The relative risk for WD in patients with SSc compared with the RG was 0.95 (95\% CI 0.39-2.33) at diagnosis, and increased to 2.09 (95\% CI 1.17-3.73) after 1 year and $2.41(1.28-4.55)$ after 3 years of followup.

During the followup, there was a tendency that net days of SL decreased, but net days of DP increased (Figures 3B and 3C). In 4 patients, SL had changed to $100 \%$ DP, which meant a more permanent form of sickness benefit. DP increased significantly between Year 1 and Year $3(\mathrm{p}=0.006)$ and between Year 2 and Year $3(\mathrm{p}=0.028)$. All patients with fulltime WD during the first year after disease onset received fulltime DP the following years.

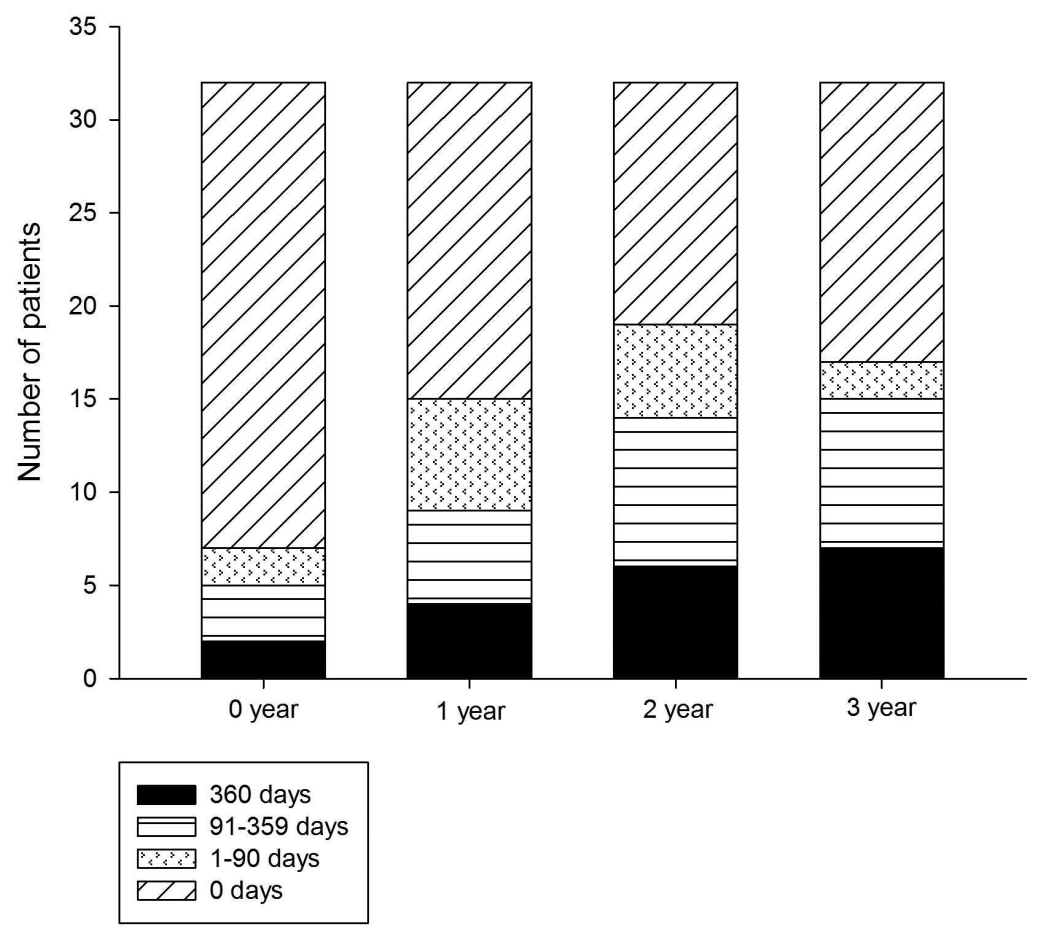

Figure 2. Number of net days of work disability per year. 


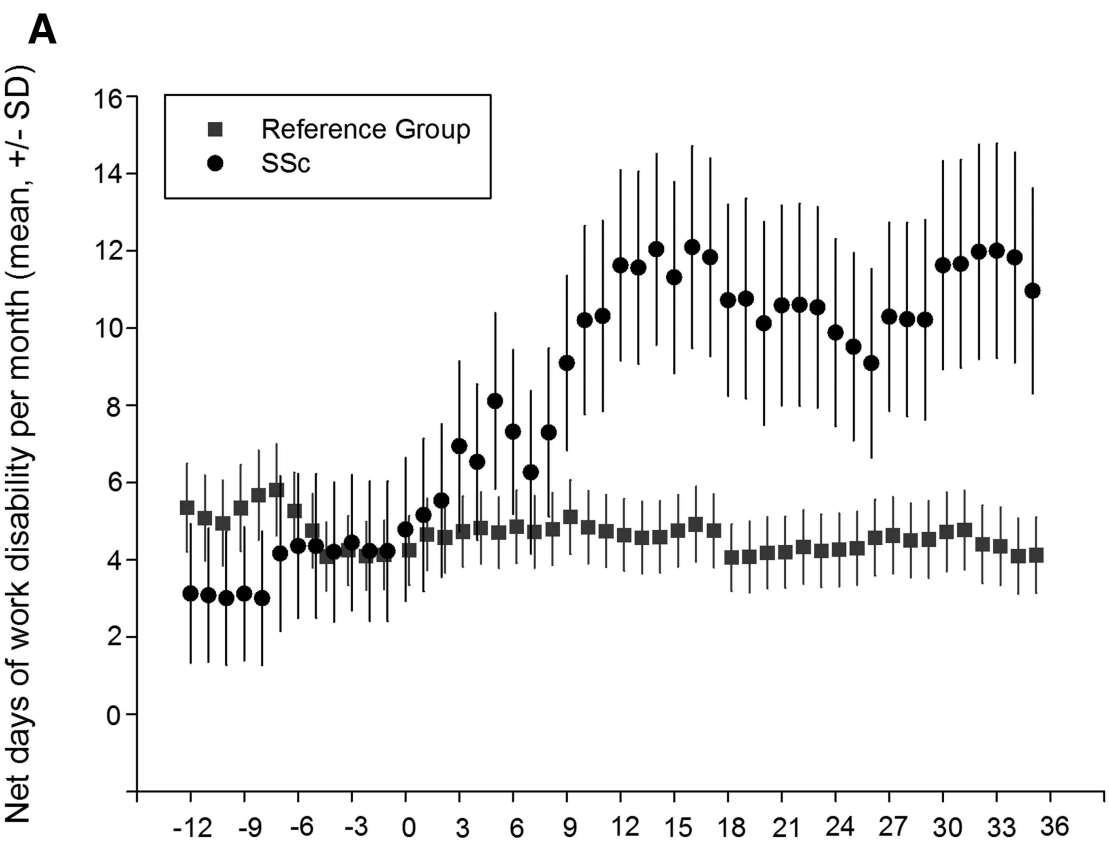

Months in relation to SSc onset

B

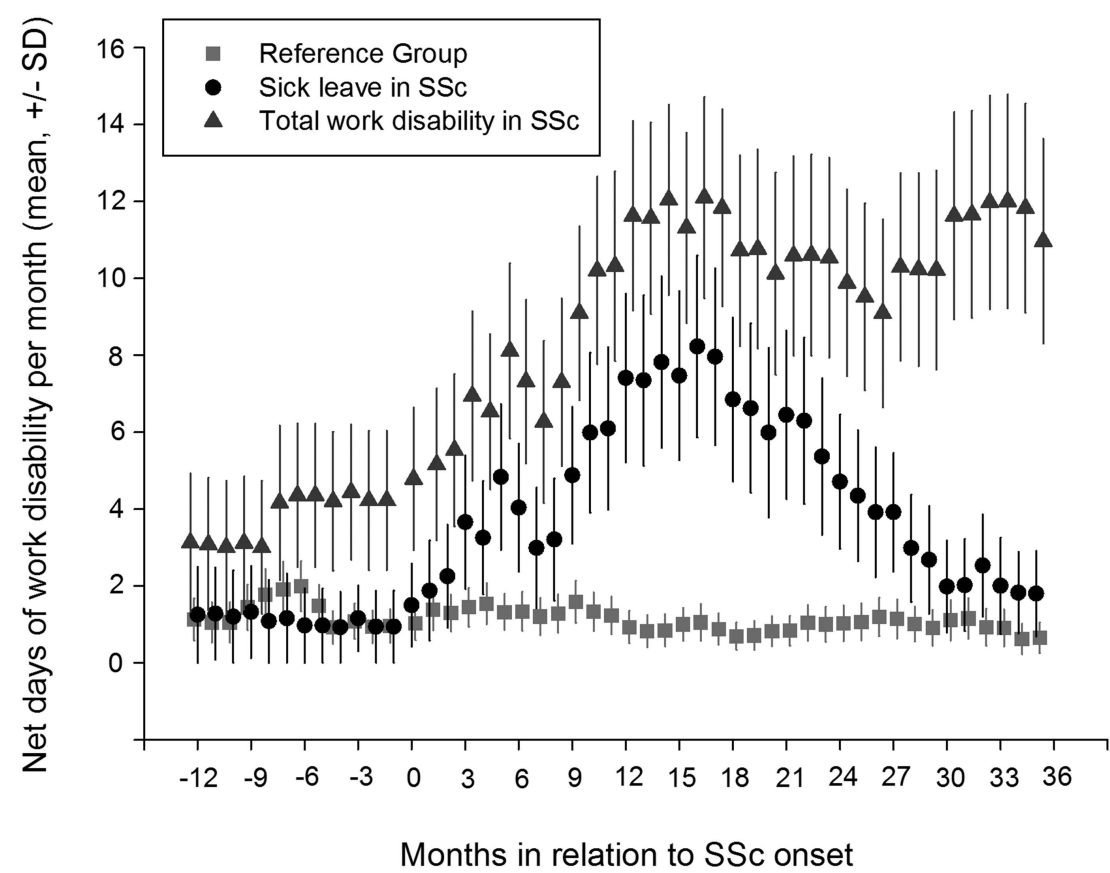

Figure 3. A. Number of net days of total WD (SL and DP) per 30-day periods (mean \pm SD) for patients with SSc and the reference group (RG) in the period 1 year prior until 3 years after disease onset. B. Number of net days of SL and total WD per 30-day periods (mean \pm SD) for patients with $\mathrm{SSc}$ and the RG in the period 1 year prior until 3 years after disease onset.

Factors with associations to sickness absence during the first 3 years after disease onset. The number of net days with WD varied greatly in the individual but also between patients. The "overall WD" during years 1-3 was mean 103 (SD 130) in
lcSSc and 190 (SD 151) in dcSSc. At the end of our study, 4 of 8 patients with dcSSc and 3 patients with $\mathrm{lcSSc}$ had fulltime established WD. No disease variable had significant correlations to the overall WD. The number of years in the

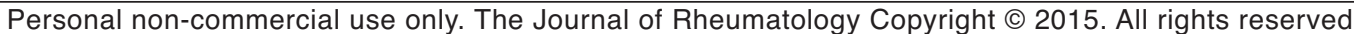




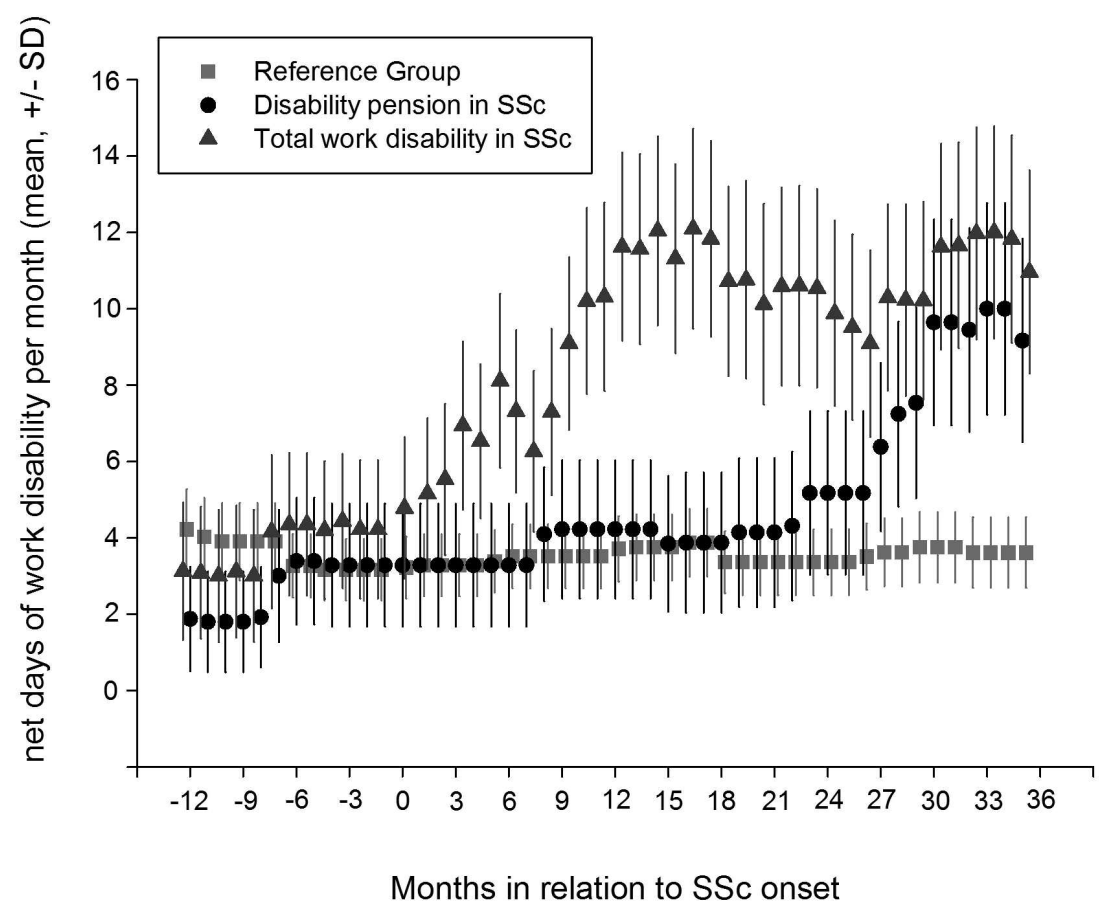

Figure 3. C. Number of net days of DP and total WD per 30-day periods (mean \pm SD) for patients with SSc and the RG in the period 1 year prior until 3 years after disease onset. WD: work disability; SL: sick leave; DP: disability pension; SSc: systemic sclerosis.

workplace, the level of education, and physically demanding work seemed to be factors with influence on WD (Figure 4). Number of years in the workplace was only available for 16 patients, but there were no statistical differences in baseline characteristics or WD status between patients with this information compared with those missing it. Significant correlations were found between overall WD over all 3 years and years at workplace $\left(\mathrm{r}_{\mathrm{s}}=-0.72 ; \mathrm{p}=0.002\right)$, the level of education $\left(r_{s}=-0.51 ; p=0.004\right)$, and sickness absence the month before disease onset $\left(r_{s}=0.58 ; p=0.001\right)$. No significant correlations were found with age or sex. There is often a relationship between education and physically demanding work. In our study, 8 of the 12 patients with primary education had physically demanding work, and there was a significant correlation between professions and education $\left(r_{s}=-0.62 ; \mathrm{p}=0.001\right)$.

\section{DISCUSSION}

In our longitudinal observational cohort study, we demonstrated that WD in patients with rather mild SSc is equal to that of the general population at disease onset, but that it increases already during the first year compared with the background population. The rise in WD is notable, from $22 \%$ with some degree of absence the year before disease onset to $47 \%$ with WD of 90 days or more 3 years after disease onset. Moreover, fewer years of education, as well as fewer years at the workplace, seem to be risk factors for sustained WD. In contrast, disease characteristics were poorly associated with the degree of WD. The results are in line with previous cross-sectional studies reporting WD of $28-43 \%$ the first 2 years of SSc ${ }^{13,14}$. Compared with the general population, at Year 1 of followup, the patients with SSc had a 2-fold increased risk of being work disabled, mainly taking SL. This relative risk further increased to 2.4 after 3 years, but at that point, SL in some cases had progressed to DP. This trend of patients converting from SL to DP was also found in early RA during the first 3 years after disease onset ${ }^{3,21}$. Longstanding WD is considered a risk factor for the inability to return to work. Although medical therapy is successful and reduces disease activity, it can be hard for the individual to return to work. Studies conducted in the same catchment area as the current study have shown that patients with chronic arthritis with a disease duration of $>5$ years had a 4 -fold relative risk for WD despite treatment with tumor necrosis factor therapy $22,23,24$.

Several factors probably influence this tendency of increased rates of DP. One is the health insurance system and other social insurance systems. However, because of changes in the social insurance regulations, the overall level of both SL and DP significantly decreased in Sweden ${ }^{25}$. Notably, the relationship between disease symptoms and work performance were not entirely clear, except for the number of net days of WD having a trend for being higher in dcSSc than in lcSSc. At baseline, patients with dcSSc had higher skin score and more limited hand function than patients with lcSSc. Previous studies have reported that dcSSc, pulmonary

Personal non-commercial use only. The Journal of Rheumatology Copyright $\odot$ 2015. All rights reserved 

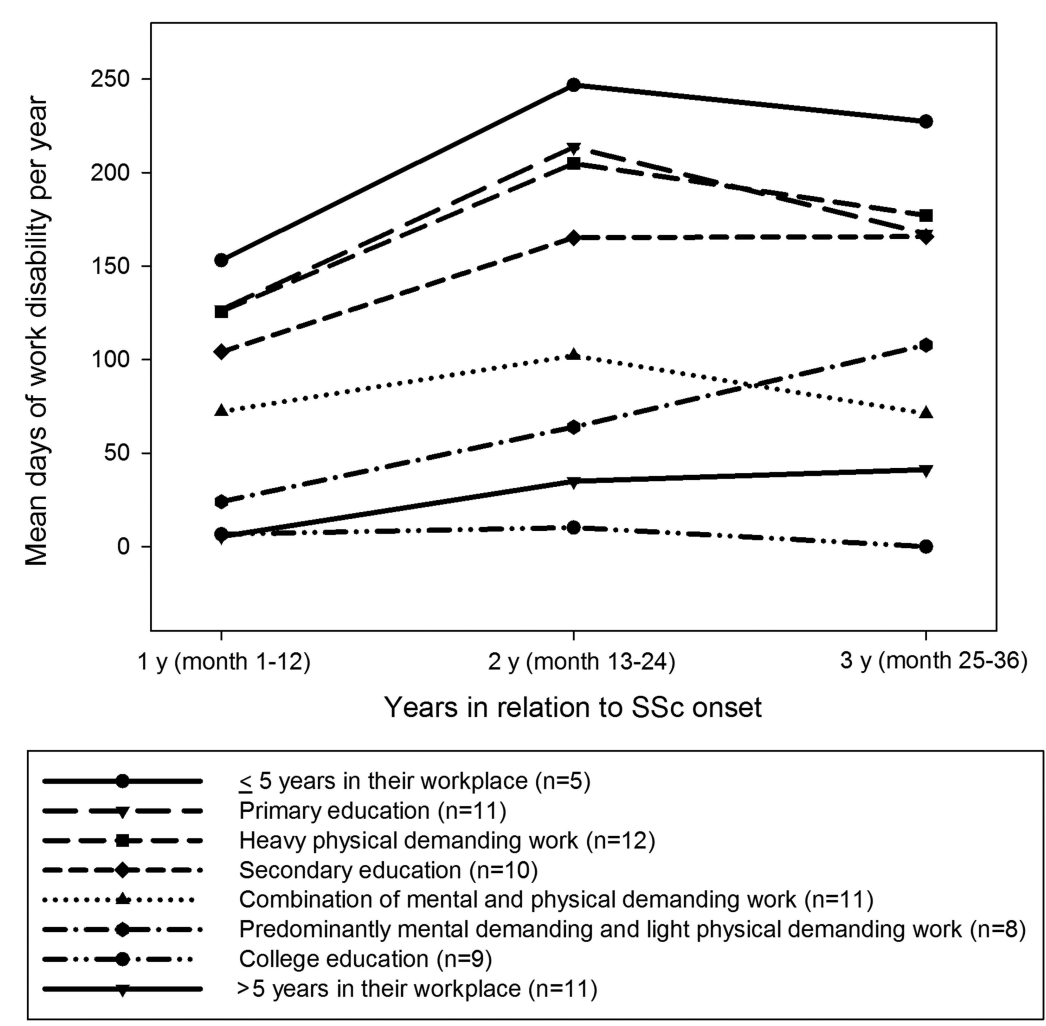

Figure 4. Number of net days of work disability per year (Yr 1 = 1-12 mos after disease onset, Yr 2 = 13-24 mos after disease onset, Year 3 = 25-36 mos after disease onset) in patients with different sociodemographic characteristics during the followup period. SSc: systemic sclerosis.

function, myalgia, fatigue, and pain also influence work ability in early disease ${ }^{11,13,14,26}$. However, biomedical variables do not consistently predict WD. Our results, as well as those of Sharif, et l $^{14}$, indicate that physically demanding work and a lower level of education are risk factors for WD in SSc. Education is also an important factor for WD in early arthritis ${ }^{3}$, as well as in $\mathrm{SLE}^{27}$. A possible explanation could be that low education level may limit the flexibility to change work tasks and remain employed, which in turn may result in a more permanent WD. Hard physical work can also be difficult to facilitate with adaptions, and patients may find it hard to ask colleagues for help. However, support from colleagues and employers is important in maintaining work $^{14,28,29}$. Many years in a workplace could mean solidity and security in the working group, facilitating support that may explain our results concerning the relationship between years at the workplace and work ability. A multidisciplinary approach early in the disease course, focusing on the patient's working tasks, work environment, and support, as well as coping strategies to handle pain and fatigue, may be an important strategy to prevent this negative trend toward DP.

There are some potential limitations to our work. The results from our longitudinal study are in many ways similar to those from larger cross-sectional studies. However, our small sample size restricts the use of certain statistical analyses, such as multivariate analyses, which may hamper the ability to detect disease-related and other predictors of WD. In addition, there was a low percentage of dcSSc cases. However, reflecting the composition of our cohort, the prevalence of $1 c S S c$ in the Skåne region was $82 \%$ in December $2010^{6}$. Another limitation is that our data on disease severity did not include information about patient-reported clinical outcomes (e.g., pain, fatigue, and shortness of breath) that may influence WD. A strength of our study was that the data on SL and DP came from an independent prospective collected source rather than from self-reports. Another strength was that the population-based study design further elucidated the burden of SSc.

Increased WD occurs in the first year after disease onset, and becomes more permanent in $47 \%$ of the patients with SSc 3 years after disease onset, primarily because of increased levels of DP. Limited education and fewer years in the workplace seem to be risk factors for sustained WD.

\section{ACKNOWLEDGMENT}

The authors thank Minna Willim for assistance with data management.

\section{REFERENCES}

1. Allaire S, Wolfe F, Niu J, LaValley MP, Zhang B, Reisine S. Current risk factors for work disability associated with rheumatoid arthritis:

$$
\text { Personal non-commercial use only. The Journal of Rheumatology Copyright (c) 2015. All rights reserved. }
$$


recent data from a US national cohort. Arthritis Rheum 2009;61:321-8.

2. Mau W, Listing J, Huscher D, Zeidler H, Zink A. Employment across chronic inflammatory rheumatic diseases and comparison with the general population. J Rheumatol 2005;32:721-8.

3. Björk M, Thyberg I, Rikner K, Balogh I, Gerdle B. Sick leave before and after diagnosis of rheumatoid arthritis - a report from the Swedish TIRA project. J Rheumatol 2009;36:1170-9.

4. Burton W, Morrison A, Maclean R, Ruderman E. Systematic review of studies of productivity loss due to rheumatoid arthritis. Occup Med 2006;56:18-27.

5. Olofsson T, Petersson IF, Eriksson JK, Englund M, Simard JF, Nilsson JA, et al. Predictors of work disability during the first 3 years after diagnosis in a national rheumatoid arthritis inception cohort. Ann Rheum Dis 2014;73:845-53.

6. Andréasson K, Saxne T, Bergknut C, Hesselstrand R, Englund M. Prevalence and incidence of systemic sclerosis in southern Sweden: population-based data with case ascertainment using the 1980 ARA criteria and the proposed ACR-EULAR classification criteria. Ann Rheum Dis 2014;73:1988-92.

7. Steen VD, Medsger TA Jr. Severe organ involvement in systemic sclerosis with diffuse scleroderma. Arthritis Rheum 2000; 43:2437-44.

8. Sandqvist G, Eklund M, Åkesson A, Nordenskiöld U. Daily activities and hand function in women with scleroderma. Scand $\mathrm{J}$ Rheumatol 2004;33:102-7.

9. Richards HL, Herrick AL, Griffin K, Gwilliam PD, Loukes J, Fortune DG. Systemic sclerosis: patients' perceptions of their condition. Arthritis Rheum 2003;49:689-96.

10. Bassel M, Hudson M, Taillefer SS, Schieir O, Baron M, Thombs BD. Frequency and impact of symptoms experienced by patients with systemic sclerosis: result from a Canadian National Survey. Rheumatology 2011;50:762-7.

11. Quimet JM, Pope JE, Gutmanis I, Koval J. Work disability in scleroderma is greater than in rheumatoid arthritis and is predicted by high HAQ scores. Open Rheumatol J 2008;2:44-52.

12. Sandqvist G, Scheja A, Eklund M. Working ability in relation to disease severity, everyday occupations and well-being in women with limited systemic sclerosis. Rheumatology 2008;47:1708-11.

13. Hudson M, Steele R, Lu Y, Thombs BD; Canadian Scleroderma Research Group, Baron M. Work disability in systemic sclerosis. J Rheumatol 2009;36:2481-6.

14. Sharif R, Mayes MD, Nicassio PM, Gonzalez EB, Draeger H, McNearney TA, et al; GENISOS Study Group. Determinants of work disability in patients with systemic sclerosis: a longitudinal study of the GENISOS cohort. Semin Arthritis Rheum 2011; 41:38-47.

15. Hultin H, Lindholm C, Malfert M, Möller J. Short-term sick leave and future risk of sickness absence and unemployment - the impact of health status. BMC Public Health 2012;12:861.
16. Preliminary criteria for the classification of systemic sclerosis (scleroderma). Subcommittee for scleroderma criteria of the American Rheumatism Association Diagnostic and Therapeutic Criteria Committee. Arthritis Rheum 1980;23:581-90.

17. de Zwart BC, Broersen JP, van der Beek AJ, Frings-Dresen MH, van Dijk FJ. Occupational classification according to work demands: an evaluation study. Int J Occup Med Environ Health 1997;10:283-95.

18. Clements PJ. Measuring disease activity and severity in scleroderma. Curr Opin Rheumatol 1995;7:517-21.

19. Sandqvist G, Eklund M. Hand Mobility in Scleroderma (HAMIS) test: the reliability of a novel hand function test. Arthritis Care Res 2000;13:369-74.

20. Nordenskiöld U, Grimby G. Grip force in patients with rheumatoid arthritis and fibromyalgia and in healthy subjects. A study with the Grippit instrument. Scand J Rheumatol 1993;22:14-9.

21. Neovius M, Simrad J, Askling J; ARTIS Study Group. How large are the productivity losses in contemporary patients with RA, and how soon in relation to diagnosis do they develop? Ann Rheum Dis 2011;70:1010-15.

22. Kristensen LE, Petersson IF, Geborek P, Jöud A, Saxne T, Jacobsson LT, et al. Sick leave in patients with ankylosing spondylitis before and after anti-TNF therapy: a population-based cohort study. Rheumatology 2012:51:243-9.

23. Olofsson T, Englund M, Saxne T, Jöud A, Jacobsson LT, Geborek P, et al. Decrease in sick leave among patients with rheumatoid arthritis in the first 12 months after start of treatment with tumour necrosis factor antagonists: a population-based controlled cohort study. Ann Rheum Dis 2010;69:2131-6.

24. Kristensen LE, Englund M, Neovius M, Askling J, Jacobsson LT, Petersson IF. Long-term work disability in patients with psoriatic arthritis treated with anti-tumour necrosis factor: a population-based regional Swedish cohort study. Ann Rheum Dis 2013;72:1675-9.

25. Lidwall U. Termination of sickness benefits or transition to disability pension after changes in sickness insurance: a Swedish register study. Disabil Rehabil 2013;35:118-24.

26. Nguyen C, Poiraudeau S, Mestre-Stanislas C, Rannou F, Bérezné A, Papelard A, et al. Employment status and socio-economic burden in systemic sclerosis: a cross-sectional survey. Rheumatology 2010;49:982-9.

27. Al Dhanhani AM, Gignac MA, Su J, Fortin PR. Work disability in systemic lupus erythematosus. Arthritis Rheum 2009;61:378-85.

28. Sandqvist G, Hesselstrand R, Scheja A, Håkansson C. Managing work life with systemic sclerosis. Rheumatology 2012;51:319-23.

29. Mendelson C, Poole JL, Allaire S. Experiencing work as a daily challenge: the case of scleroderma. Work 2013;44:405-13. 